\title{
A invenção de Humboldt \\ Desvendando o eurocentrismo e seus significados
}

\section{Humboldt's Invention}

Unraveling Eurocentrism and its Meanings

\section{Marcio Antônio Both da SiLVA*}

Obra resenhada:

WULF, Andrea. A Invenção da Natureza. A vida e as descobertas de Alexander von Humboldt. São Paulo: Crítica, 2019. 587 p.

Esta resenha tem por motivo apresentar os conteúdos e temas abordados ao longo do livro A Invenção da Natureza: a vida e as descobertas de Alexander von Humboldt, de autoria da jornalista e escritora Andrea Wulf. O livro trata da vida e da trajetória de um personagem muito interessante no contexto do século XIX, reconhecido por suas investigações científicas, as quais influenciaram intelectuais e cientistas de diferentes partes do mundo. Considerado um dos principais pensadores envolvidos na constituição da nossa atual concepção de ecologia e meio ambiente, a obra de Alexander von Humboldt continua inspirando o pensamento ecológico nos dias de hoje. Além disso, no contexto dos 250 anos de seu nascimento, ocorrido em 2019, esse pensador e sua obra foram revisitados de forma bastante significativa, seja por pesquisadores

* https://orcid.org/0000-0001-6613-1335

Universidade Estadual do Oeste do Paraná (UNIOESTE), Colegiado de História Rua Pernambuco, 1777, Marechal Cândido Rondon, PR, 85960-000, Brasil marcioboth@gmail.com 
vinculados ao universo da pesquisa acadêmica, seja por curiosos, jornalistas e escritores em geral.

Quem foi Alexander von Humboldt? Quais foram suas contribuições para o desenvolvimento da ciência e da pesquisa científica? Qual sua influência na constituição da nossa ideia de meio ambiente e da necessidade de sua preservação? Essas, dentre outras, são algumas das perguntas que podem ser respondidas a partir da leitura de $A$ Invenção da Natureza, livro que foi publicado no Brasil em 2016 pela Editora Crítica e, em 2019, conheceu sua segunda edição. A versão original em inglês, datada de 2015, recebeu reconhecidas premiações e também foi considerado o melhor livro de não ficção por The New York Times, The Guardian e Revista Time. No que diz respeito à biografia da autora, ela apresenta-se como escritora e historiadora e é formada em História do Design pelo Royal College of Art de Londres. Além disso, trabalha regularmente para o canal de televisão inglês BBC e realiza publicações frequentes em jornais como The Guardian, Sunday Times, Financial Times, LA Times e o Wall Street Journal (WULF, 2019b).

A obra aqui resenhada é o quinto de uma série de livros publicados por Wulf entre 2005 e 2019, os quais têm como foco a ciência, o conhecimento científico e os cientistas. É o primeiro que tem Humboldt como tema central, sendo que em 2019, juntamente com a ilustradora Lillian Melcher, lançou a história em quadrinhos The Adventures of Alexander von Humboldt, ainda não traduzido no Brasil.

A Invenção da Natureza está dividido em cinco partes e é composto por 22 capítulos, nos quais Wulf busca contar a história e a trajetória intelectual e pessoal de Alexander von Humboldt, nascido em Berlim em 14 de setembro de 1769. Para dar conta do objetivo, a autora não só toma por fonte de análise a obra do biografado e seus diários pessoais, como também faz uso de anotações e comentários realizados por alguns dos seus mais destacados leitores, tais como Johann Wolfgang Goethe e Charles Darwin.

O ponto de partida da obra é a origem familiar e social de Humboldt, mas a caminhada verdadeiramente inicia quando a autora passa a descrever o seu processo de formação intelectual e seus primeiros 
contatos com o saber científico e a literatura. Nessa perspectiva, a história ganha conteúdo e significados particulares quando Wulf relata a viagem que Humboldt encetou ao continente americano na virada do século XVIII para o XIX (1799-1804), quando contava com 30 anos de idade. Trata-se do momento em que ele passou a desenvolver sua concepção de natureza, a qual teve impactos significativos no mundo intelectual do século XIX e, segundo a autora, constitui-se no cerne da nossa concepção de natureza.

A grande descoberta de Humboldt, registra Wulf, foi a de que a terra é um grande organismo vivo. Essa ideia começou a tomar formato na experiência que ele viveu na América Latina e foi confirmada na viagem que fez de uma ponta à outra da Rússia em 1829, já aos 60 anos. Nos termos da autora, Humboldt "revolucionou a nossa forma de ver o mundo natural", pois "descobriu conexões e relações por toda parte." Para ele, tudo estava interconectado e "nada, nem mesmo o mais diminuto organismo, era visto de forma independente e separada." Segundo Wulf, "com essa arguta constatação", Humboldt "inventou a rede da vida, o conceito de natureza como o conhecemos hoje" (WULF, 2019a, p. 28).

Todavia, a história de Humboldt não se encerra nessa "descoberta" que foi profundamente impactante em sua época, mas que, para nós, de tanto repetida, transformou-se em saber comum a ponto de pouco ou mesmo não lembrarmos que ela tem uma história e que foi construída com base em muito trabalho de pesquisa e de troca de saberes. Assim, outro ponto forte do livro é a análise das influências que as pesquisas de Humboldt tiveram ao longo do século XIX e do XX. Homens como Johann Wolfgang Goethe, Charles Darwin, Hernry David Thoreau, George Perkins Marsh, Ernst Haeckel, John Muir, dentre outros, segundo Wulf, tiveram Humboldt e sua obra como fontes de inspiração.

A influência humboldtiana, do mesmo modo, estendia-se e teve diferentes usos no universo da política. Nesse caso, Wulf destaca o lugar de Humboldt e de sua obra na formação e nas trajetórias políticas de pessoas como Simón Bolivar e Thomas Jefferson, homens com os quais ele manteve contato pessoal e, de acordo com a autora, inspirou algumas ações. Ela também localiza esse traço na produção bibliográfica 
de Humboldt, na qual a crítica ao mundo de sua época ocupa posição destacada, em especial à existência da escravidão no continente americano, ao domínio colonial e ao modo predatório como os homens vinham se relacionando com a natureza.

A autora relata que as análises de Humboldt sobre esses temas eram tão contundentes que acabaram por impactar sua vida de pesquisador. Nesse sentido, uma das exigências feitas pelo Czar Nicolau I para autorizar sua excursão pela Rússia foi a de que nos seus relatos não fossem abordadas questões sociais e políticas, mas somente científicas. Determinação que, por sua vez, não foi devidamente cumprida. Do mesmo modo, sua leitura crítica da sociedade foi responsável por fazer com que a Companhia das Índias Orientais não autorizasse a viagem na qual pretendia conhecer e estudar a natureza do Himalaia, mesmo mediante o reconhecimento intelectual que possuía e da interferência de algumas autoridades inglesas. Humboldt faleceu em 6 de maio de 1859, sem poder realizar esse sonho.

O livro de Wulf também apresenta como, ao longo de sua carreira e por meio de sua produção bibliográfica, Humboldt se tornou um dos homens mais influentes e reconhecidos de sua época, a ponto de, em 1869, no centenário de seu nascimento, serem realizados eventos em diferentes paragens do mundo. Recentemente, na véspera do aniversário de 250 anos de nascimento de Humboldt, o fenômeno se repetiu por meio da edição de biografias e histórias que têm o naturalista alemão como personagem. É o caso da obra de Wulf, mas também do livro The Passage to Cosmos: Alexander Von Humboldt and the shaping of America de Laura Dassow Walls, datado de 2009 e ainda não traduzido no Brasil, entre vários outros exemplos.

De acordo com Wulf (2019a, p. 459), a relevância de Humboldt se deve ao fato de que ele influenciou "não somente alguns dos mais importantes pensadores, cientistas e artistas, mas eles por sua vez inspiravam uns aos outros". Assim, a leitura de A Invenção da Natureza nos faz conhecer um Humboldt pesquisador que primava pela interdisciplinaridade e acreditava que o conhecimento científico poderia ser de grande utilidade para melhorar o mundo e a vida em sociedade. 
Contudo, é preciso ter muito cuidado em relação a algumas dessas afirmações e, em algum sentido, aos significados do livro de Wulf como um todo. O primeiro aspecto que é importante destacar é o de que, ao final da leitura, fica-se com a impressão de que Humboldt era perfeito demais. No livro há quase que uma completa ausência de críticas ao biografado e sua obra. Nesse sentido, a narrativa como um todo é construída sob a perspectiva de que Humboldt era uma espécie de "homem à frente de seu tempo", um iluminado. Demonstra isso a insistência da autora em registrar que ele foi o primeiro a fazer e a descobrir uma série de coisas, caindo na "ilusão biográfica" (BOURDIEU, 2006), na heroicização do biografado.

Nessa mesma linha, algumas análises sobre o $\mathrm{A}$ Invenção da $\mathrm{Na}$ tureza têm demonstrando o quanto Andrea Wulf partilha de uma visão eurocêntrica sobre Humboldt, sua trajetória e seus estudos. Além disso, há o problema das omissões, pois algumas descobertas que são atribuídas originalmente a Humboldt, na verdade já vinham sendo objeto de discussão em outros contextos e por outros pesquisadores, há bastante tempo e com maior qualidade. Mais detidamente por intelectuais latino-americanos, contudo, eles não são mencionados, tanto por Humboldt como por seus biógrafos (ESGUERRA, 2019).

Ao tratar desse tema, José Augusto de Pádua (2004, p. 28-30) destaca o protagonismo das regiões coloniais e de seus intelectuais no desenvolvimento da "crítica ambiental moderna". Ele não deixa de registrar a importância do trabalho de Humboldt, especialmente seu empenho em produzir uma "visão comparativa dos ambientes naturais em escala planetária" e como a perspectiva cosmológica humboldtiana, somada à produção de outros pensadores que se dedicaram a tratar da relação do homem com o ambiente natural (inclusive os que viviam no contexto das colônias), influenciou no desenvolvimento daquilo que hoje chamamos de "pensamento ecológico". Na mesma perspectiva, as pesquisas de Richard Grove (1990) sobre a questão têm apontado certo pioneirismo das regiões coloniais nos debates sobre a destruição ambiental e seus impactos. Nesse contexto, estudos como o de Pádua e Grove também têm destacado o quanto o conhecimento sobre o meio 
ambiente, produzido no universo das colônias, não foi devidamente reconhecido na Europa.

Esse é o caso, por exemplo, da ausência de referências ao cientista colombiano Francisco José Caldas nas primeiras publicações de Humboldt, muito embora ele conhecesse a obra de Caldas e soubesse do seu protagonismo na discussão de alguns temas. Segundo Esguerra (2019), Humboldt só reconheceu a importância de Caldas tardiamente na edição de seu Geografia das Plantas de 1826, e isso em uma pequena nota de pé-de-página. Esguerra destaca ainda as críticas que o próprio Caldas produziu na época a algumas interpretações desenvolvidas por Humboldt sobre a natureza latino-americana, principalmente aos mapas que ele elaborou do vulcão Chimborazo, localizado no Equador. De acordo com Caldas, os mapas do naturalista alemão eram "bonitos, porém errados". Como contraprova, apresentava a cartografia do Chimborazo por ele elaborada, mais precisa e fruto de longos anos de observação, diferentemente de Humboldt, que havia escalado a montanha uma única vez.

Do mesmo modo, as influências intelectuais e as críticas sociais e políticas de Humboldt devem ser relativizadas. Sua desaprovação ao colonialismo não o impossibilitou de explorar mão de obra indígena durantes suas viagens pela América Latina, ou mesmo receber apoio de notórios escravagistas para custear seus estudos. Ainda nesse sentido, sua defesa da República não o impediu de ter como principal fonte de renda um déspota prussiano (ESGUERRA, 2019).

Embora essas situações estejam presentes na obra de Wulf, especialmente a vinculação de Humboldt com a corte prussiana, ela é apresentada como a alternativa que o biografado encontrou para financiar seus estudos. Não tivesse cedido em alguns de seus princípios, quem perderia, ao fim e ao cabo, seria a humanidade como um todo, pois não teria ou demoraria mais a ter acesso às "descobertas" feitas por Humboldt, as quais, vale destacar, não eram tão dele assim. Como demonstram Esguerra, Pádua e Grove, elas se inserem em um processo histórico mais amplo e envolvem uma complexa troca de saberes. Portanto, o Humboldt que é apresentado como o grande pensador do século XIX, 
como "o sábio que passou cinco anos viajando na América espanhola e que aparece como o inventor de tudo", que em muitos contextos é apresentado e considerado como o "pai da psicologia moderna, da estética, da antropologia cultural, da crítica ecológica”" (ESGUERRA, 2019) é, na verdade, uma invenção.

De todo modo, mesmo diante dessas questões, vale destacar a relevância do livro A Invenção da Natureza de Andrea Wulf. Sua leitura é válida, pois apresenta ao leitor uma série de temas que são muito importantes, que foram pauta de discussão em um passado não muito distante. Assuntos que tem muito a dizer sobre o mundo contemporâneo, seus problemas, experiências e perspectivas de futuro, especialmente no que diz respeito à relação do homem com o meio ambiente. Constatação que, neste momento em que a humanidade é assolada por uma pandemia (ano de 2020), ganha ainda mais importância.

Entretanto, os aprendizados ficarão mais completos quando levarmos em consideração que o livro de Wulf tem uma série de lacunas e problemas e que há perigo neles. O principal, como demonstra Jorge Esguerra (2019), é o seu eurocentrismo que, assim como acontece na obra de Humboldt, insiste em pensar e apresentar o sul do mundo como o lugar da natureza. Em contrapartida, o norte global é tratado como o lugar das ideias, da civilização, portanto, do progresso e do desenvolvimento. Nesse caso, a obra de Wulf, mais precisamente a sua crítica, pode nos ajudar a avançar no sentido de perceber o quanto, "desde Humboldt, a má distribuição geopolítica da autoridade epistemológica global permanece firmemente enraizada" 2 . Da mesma forma, o quanto algumas leituras historiográficas vêm contribuindo e sendo responsáveis pela manutenção dessa característica (ESGUERRA, 2019).

1 Trad. livre do autor: "The sage who spent five years traveling in Spanish America appears as the inventor of everything. The German "gay" scholar allegedly was the father of modern psychology, aesthetics, cultural anthropology, ecological criticism, and good taste".

2 Trad. livre do autor: "since Humboldt the geopolitical ill distribution of global epistemological authority remains firmly entrenched". 


\section{Agradecimentos}

Esta resenha é resultado de pesquisa de pós-doutoramento que recebe apoio do Conselho Nacional de Desenvolvimento Científico e Tecnológico (CNPq) e do INCT-Proprietas.

\section{REFERÊNCIAS BIBLIOGRÁFICAS}

BOURDIEU, Pierre. A ilusão biográfica. In: AMADO, Janaína; FERREIRA, Marieta de Moraes (Orgs.). Usos e abusos de história oral. Rio de Janeiro: FGV, 2006. p. 183-191.

ESGUERRA, Jorge Canizares. Screwing Humboldt and his hagiographers. Medium, 27 Sep. 2019. Disponível em: <https://medium.com/@jorge canizaresesguerra/screwing-in-two-positions-82c2cc5b09db $>$. Acesso em: 20 abr. 2020.

GROVE, Richard. Colonial conservation, ecological hegemony and popular resistance: towards a global synthesis. In: MACKENZIE, John M. (Org.). Imperialism and the Natural World. Manchester: Manchester University Press, 1990. p. 15-50.

PADUA, José Augusto. Um sopro de destruição. Pensamento político e crítica ambiental no Brasil escravista (1786-1888). Rio de Janeiro: Zahar, 2004. WALLS, Laura Dassow. The Passage to Cosmos: Alexander Von Humboldt and the shaping of America. Chicago: University of Chicago Press, 2009. WULF, Andrea. A Invenção da Natureza. A vida e as descobertas de Alexander von Humboldt. São Paulo: Crítica, 2019a.

WULF, Andrea. A autora "best-seller"Andrea Wulf esclarece o que o gênio universal Alexander von Humboldt tem que ver com a mudança de clima e sustentabilidade. Entrevistadora: Sabrina Pfost. Deutschland.de, 12 set. 2019b. Disponível em: $<$ https://www.deutschland.de/pt-br/topic/conhecimento/ano-de-humboldt-2019-entrevista-com-andrea-wulf>. Acesso em: 02 jun. 2020. WULF, Andrea; MELCHER, Lillian. The Adventures of Alexander von Humboldt. New York: Phanteon Books, 2019. 